\title{
Impact of thermal stress on evolutionary trajectories of pathogen resistance in three-spined stickleback (Gasterosteus aculeatus)
}

\author{
Franziska M Schade*, Lisa NS Shama and K Mathias Wegner
}

\begin{abstract}
Background: Pathogens are a major regulatory force for host populations, especially under stressful conditions. Elevated temperatures may enhance the development of pathogens, increase the number of transmission stages, and can negatively influence host susceptibility depending on host thermal tolerance. As a net result, this can lead to a higher prevalence of epidemics during summer months. These conditions also apply to marine ecosystems, where possible ecological impacts and the population-specific potential for evolutionary responses to changing environments and increasing disease prevalence are, however, less known. Therefore, we investigated the influence of thermal stress on the evolutionary trajectories of disease resistance in three marine populations of three-spined sticklebacks Gasterosteus aculeatus by combining the effects of elevated temperature and infection with a bacterial strain of Vibrio sp. using a common garden experiment.

Results: We found that thermal stress had an impact on fish weight and especially on survival after infection after only short periods of thermal acclimation. Environmental stress reduced genetic differentiation ( $\left.\mathrm{Q}_{S T}\right)$ between populations by releasing cryptic within-population variation. While life history traits displayed positive genetic correlations across environments with relatively weak genotype by environment interactions (GxE), environmental stress led to negative genetic correlations across environments in pathogen resistance. This reversal of genetic effects governing resistance is probably attributable to changing environment-dependent virulence mechanisms of the pathogen interacting differently with host genotypes, i.e. $G_{\text {pathogen }} \times G_{\text {Hoss }} \times E$ or $\left(G_{\text {pathogen }} \times E\right) \times\left(G_{\text {Host }} \times E\right)$ interactions, rather than to pure host genetic effects, i.e. $G_{\text {Host }} \times E$ interactions.

Conclusion: To cope with climatic changes and the associated increase in pathogen virulence, host species require wide thermal tolerances and pathogen-resistant genotypes. The higher resistance we found for some families at elevated temperatures showed that there is evolutionary potential for resistance to Vibrio sp. in both thermal environments. The negative genetic correlation of pathogen resistance between thermal environments, on the other hand, indicates that adaptation to current conditions can be a weak predictor for performance in changing environments. The observed feedback on selective gradients exerted on life history traits may exacerbate this effect, as it can also modify the response to selection for other vital components of fitness.
\end{abstract}

Keywords: Climate change, Infectious diseases, Vibrio tubiashii, Genotype x environment Interaction, Selection

\footnotetext{
* Correspondence: Franziska.Schade@awi.de

Alfred Wegener Institute Helmholtz Centre for Polar and Marine Research,

Hafenstrasse 43, 25992 List/Sylt, Germany
} 


\section{Background}

Pathogens are strong selective agents that can influence biodiversity by regulating host population dynamics [1,2]. Environmental conditions can amplify these effects [3], and many infectious diseases are temperature-dependent [4]. An increase in ambient temperature will affect the pathogen by, for example, enhancing its metabolism resulting in faster development and a higher number of transmission stages per generation. Especially for many bacterial disease agents, population growth rates increase exponentially with increasing temperature $[5,6]$. Since population growth rate closely resembles fitness for prokaryotes, improved pathogen fitness can also lead to a higher prevalence of diseases [7].

Rising temperatures are also likely to stress the host organism, thereby increasing host susceptibility to diseases $[8,9]$. This also applies to marine organisms [10], which are often highly vulnerable to climatic changes [11]. Thermal stress causes an alteration of the immune response, which generally results in a reduction of pathogen resistance [12]. Despite these multifaceted effects, the specific interactions of increased thermal stress due to climatic warming with infectious diseases are sparsely explored, particularly in marine ecosystems.

The ecological and evolutionary consequences of thermal stress-disease interactions will strongly depend on the thermal tolerance and rate of adaptation of populations to climate warming [13]. A high potential for acclimation within and between generations and the capacity for adaptation by selection of pathogen-resistant genotypes will ensure population viability and biodiversity $[14,15]$. Species with rapid turnover of generations are likely to adapt fast enough to cope with the changing environment [16]. For vertebrates, the potential for adaptation by microevolution is considered to be alarmingly low [17]. Standing genetic variation supplies the raw material for adaptation, and different genotypes will show different reaction norms leading to genotype by environment (GxE) interactions. GxE interactions as well as phenotypic plasticity can potentially compensate for declines in mean fitness of populations with low evolutionary potential. Furthermore, it also has been shown that changing environmental conditions can release otherwise cryptic genetic variation [18], which can consequently alter the evolutionary potential of a population.

Here, we tested whether environmental change can also alter the genetic components of resistance to pathogen challenges, and whether such changes can feed back on selection gradients of other components of fitness. To do so, we set up a common garden breeding experiment using three populations of marine three-spined sticklebacks Gasterosteus aculeatus and challenged the offspring with an infection by a bacterial strain of Vibrio sp. in two different temperature environments (ambient and stressful). In general, bacteria of the genus Vibrio include many facultative symbionts and pathogenic strains [19]. They are strongly temperature-dependent with elevated population sizes during summer [20,21]. Moreover, they are able to adapt rapidly to environmental changes due to high genome plasticity including frequent mutation, recombination and lateral gene transfers [22], making them ideal candidates for our purpose to study hostparasite interactions in changing environments. Vibrio tubiashii, in particular, has been described as a pathogen of bivalves [23,24], but is also known to harm several marine fish species [25,26], where Vibriosis can lead to superficial skin lesions, muscle necrosis and haemorrhages which are likely to cause mortality [27].

The three-spined stickleback represents an ideal model system to study the evolutionary ecology of host-parasite interactions [28-30] especially in connection with environmental change. These fish occur in shallow freshwater and marine habitats with a temperature range from 4 to $20^{\circ} \mathrm{C}$ [31], but show preferences for intermediate temperatures $\left(15-18^{\circ} \mathrm{C}[32,33]\right)$. Our experimental temperature environments were set to simulate the average summer temperature of coastal North Sea areas (i.e. $17^{\circ} \mathrm{C}$ ) and elevated temperatures with reference to recent climate change predictions for the North Sea $\left(21^{\circ} \mathrm{C}\right)$ [34], which was shown to result in diminished growth rates after long-term exposure in one of the populations used here [35].

With this study, we estimated the effects of thermal stress on pathogen resistance (i.e. survival after infection) and its interactions with other life history traits that can affect an individual's survival and reproductive potential. In a narrower sense, life history traits include gestation time, age to sexual maturity, reproductive life span and number of progeny. In a wider sense, morphological traits such as length and weight can also be seen as life history traits representing key maturational and reproductive characteristics, and we thus chose to also measure size and weight.

Short-term fluctuations and extreme events like heat waves that are predicted to increase in the nearer future [36] could have very different effects on populations with different adaptive thermal optima. By additionally determining the within- and between-population genetic components of resistance and life history traits, we can also project if environmental stress will modify the results of population-specific evolutionary trajectories by releasing or absorbing genetic variance for traits under selection. The connection between environmentally modified pathogen-induced selection to its consequences for other components of fitness will help to deepen our understanding of how populations can or cannot cope with increasingly stressful and pathogen rich environments. 


\section{Methods}

\section{Sampling and fish breeding}

During April and June 2011, adult marine sticklebacks were caught by dip netting in an oyster farm in Yerseke (Oosterschelde, The Netherlands, 51.49 N, 4.06 E) and in tidal channels on the islands of Texel (The Netherlands, $53.16 \mathrm{~N}, 4.88 \mathrm{E}$ ) and Sylt (Germany, 55.03 N, 8.46 E). Between 50-70 individuals were sampled from each location and transferred in groups of 5-7 fish to 201 aquaria (38 $\times$ $25 \times 20 \mathrm{~cm}$ ) equipped with permanent seawater flowthrough at a constant temperature of $17^{\circ} \mathrm{C}$. Between July and August, laboratory-bred F1 families were produced for each population (20 families per population) using a modified North Carolina II breeding design (five replicates of crosses between two dams $\mathrm{x}$ two sires i.e. four halfsibling families). Since not all of the crosses resulted in successful hatchings, we produced additional families $(\mathrm{n}=$ 10 and using different parents) to increase sample size and achieve better estimates of within-population variation for the Sylt population. Eggs were kept in aerated 11 glass beakers until hatching. Hatchlings were then transferred to $10 \mathrm{l}$ flow through tanks $(19 \times 25 \times 20,5 \mathrm{~cm})$ with a water temperature of $17^{\circ} \mathrm{C}$ and a $16 \mathrm{~h}: 8 \mathrm{~h}$ light: dark cycle. In total, 14 families from Oosterschelde, 11 families from Texel and 24 families from Sylt hatched.

One month after hatching, the density of each family was reduced to 20 fish per $10 \mathrm{l}$ aquaria. Fish were fed daily ad libitum with live Artemia sp. until 12 weeks of age and afterwards with frozen chironomid larvae until the end of the experiment. During the early rearing phase, we lost several families due to electrical failure of aeration pumps. These affected only newly hatched families from all populations and did not lead to a systematic bias in mortality $\left(X_{2}^{2}=0.584, P=0.747\right)$. In the end, nine families remained from the Oosterschelde population $\left(\mathrm{n}_{\text {fish }}=164\right)$, nine families from Texel $\left(\mathrm{n}_{\text {fish }}=192\right)$ and 13 families from Sylt $\left(n_{\text {fish }}=263\right)$ that had sufficient family sizes (20 fish per family) for the infection experiment.

\section{Infection experiment}

Eight months after hatching, families were separated into smaller groups of 10 fish per 2,6 1 aquarium $(12 \times 18,5 \times$ $11,8 \mathrm{~cm})$. In line with recent climate change predictions for the North Sea [34], half of each family $(n=10)$ was experimentally exposed to elevated temperatures by increasing the water temperature up to $21^{\circ} \mathrm{C}$. The remaining half $(n=10)$ was kept at their rearing temperature of $17^{\circ} \mathrm{C}$ as a control. After a four week thermal acclimation period, fish from both temperature treatments were injected either with $10 \mu \mathrm{l}$ of a solution containing a bacterial strain of Vibrio sp. closely related to a pathogenic strain of Vibrio tubiashii $\left(10^{7}\right.$ cells per $\left.\mathrm{ml}, 17^{\circ} \mathrm{C} \mathrm{n}=5,21^{\circ} \mathrm{C} \mathrm{n}=5\right)$ or with the same amount of phosphate buffered saline (PBS) medium as control $\left(17^{\circ} \mathrm{C} \mathrm{n}=5,21^{\circ} \mathrm{C} n=5\right)$. Infected and control fish were then held in ambient or elevated water temperature without flow through and susceptibility was determined by monitoring induced mortality every 12 hours for 10 days. Dead fish as well as fish remaining at the end of the experiment were weighed (wet mass to the nearest $0.01 \mathrm{~g}$ ) and measured (standard length to the nearest $0.1 \mathrm{~cm}$ ). All experiments were conducted in accordance with German animal welfare laws (Permission No. V312-72241.123-16).

\section{Microsatellite genotyping}

To measure drift-based neutral divergence between populations, each parental fish $(\mathrm{n}=70)$ was genotyped at 15 microsatellite loci. DNA was extracted from the caudal fin using the DNAeasy Blood and Tissue Kit (Qiagen, Hilden). The $20 \mu \mathrm{l}$ multiplex PCR reactions consisted of $4 \mu \mathrm{l}$ of $5 \mathrm{x}$ PCR Flexi buffer, $2 \mu \mathrm{l} 10 \mathrm{mM}$ dNTP, $0.6 \mu \mathrm{l}$ $25 \mathrm{mM} \mathrm{MgCl} 2,0.1 \mu \mathrm{l} 500 \mathrm{U}$ GoTaq DNA Polymerase (all PCR chemicals from Promega, Mannheim), $5 \mathrm{pmol}$ of each fluorescently labelled forward and unlabelled reverse primer and $2 \mu \mathrm{l}$ DNA template. Thermal cycling for PCR group 1 (containing markers 5196 HEX, 4170 6_FAM, 1125 6_FAM, 1097 NED and 7033 NED, [37]) started with an initial denaturation step at $94^{\circ} \mathrm{C}$ for $3 \mathrm{~min}$ followed by 30 cycles of $94^{\circ} \mathrm{C}$ for $1 \mathrm{~min}, 58^{\circ} \mathrm{C}$ for $1 \mathrm{~min}$ and $72^{\circ} \mathrm{C}$ for $1 \mathrm{~min}$. PCR group 2 (containing markers STN 18 HEX, STN 32 6_FAM, STN 75 HEX and STN 84 NED) started with an initial denaturation step at $94^{\circ} \mathrm{C}$ for $3 \mathrm{~min}$ followed by 30 cycles of $94^{\circ} \mathrm{C}$ for $45 \mathrm{sec}$, $56^{\circ} \mathrm{C}$ for $45 \mathrm{sec}$ and $72^{\circ} \mathrm{C}$ for $1 \mathrm{~min}$. PCR group 3 (containing markers STN 2 6_FAM, STN 170 HEX and STN 174 HEX) and as well as PCR group 4 (STN 36 6_FAM, STN 114 6_FAM and STN 167 HEX, [38]) started with an initial denaturation step at $94^{\circ} \mathrm{C}$ for $2 \mathrm{~min}$ followed by $30 \mathrm{cy}$ cles of $94^{\circ} \mathrm{C}$ for $45 \mathrm{sec}, 56^{\circ} \mathrm{C}$ for $45 \mathrm{sec}, 72^{\circ}$ for $45 \mathrm{sec}$ and a final extension step at $72^{\circ} \mathrm{C}$ for $20 \mathrm{~min}$.

One $\mu \mathrm{l}$ of each PCR reaction was denatured in HiDiformamide (Life Technologies, Darmstadt) at $94^{\circ} \mathrm{C}$ for 2 min. Fragments were separated using an ABI prism 3100 XL (Life Technologies, Darmstadt) capillary sequencer. Genotype scoring was performed using GeneMarker software (SoftGenetics, version 1.91), and neutral genetic differentiation (measured as $\mathrm{F}_{\mathrm{ST}}$ ) was calculated after Weir and Cockerham [39] using the software GENETIX [40]. Significance of the observed estimates was calculated by bootstrapping using 1000 random permutations of the data. The range for the neutral marker-based differentiation in the $\mathrm{Q}_{\mathrm{ST}}-\mathrm{F}_{\mathrm{ST}}$ comparison was determined by using the extremes of the distribution of single-locus estimates of $\mathrm{F}_{\mathrm{ST}}$ for all 15 loci [41].

\section{Statistical analyses}

We used generalized linear mixed models (GLMM) using the MCMCglmm package [42] of the R statistical 
environment [43] for all of our statistical analyses. First, we wanted to determine the effects of temperature and infection as fixed effects on length, weight and survival using population and full-sibling family as random effects. Density and age were entered as covariates in all models to account for differences among families prior to our experimental treatment. We fitted models as generalized linear mixed models with length and weight as Gaussian and survival as binomial response variables. Markov chains were run for 500'000 iterations and we kept every 100th value after removing 300 '000 iterations of burn-in to generate posterior distributions of random and fixed parameters. Model fits were assessed by their respective Deviance Information Criterion (DIC) scores [44] including random effects. We used weak but informative priors of half the observed phenotypic variance and examined posterior samples from the Markov chain for signs of autocorrelation. To test for GxE interactions, we additionally fitted random slopes for random terms (singly and combined), and assessed model fit by DIC scores taking a better model fit for a full-sibling family random slopes model as an indication for $\mathrm{GxE}$ interactions.

Second, we used population and animal variance components from environment and trait specific GLMMs to calculate population and genetic differentiation in different environments. Divergence in quantitative traits $\left(\mathrm{Q}_{\mathrm{ST}}\right)$ was calculated as [45],

$$
Q_{S T}=\frac{\sigma_{B}^{2}}{\sigma_{B}^{2}+2 \sigma_{W}^{2}}
$$

where $\sigma_{B}^{2}$ and $\sigma_{W}^{2}$ are the between- and withinpopulation components of genetic variation. The animal variance component was taken as the measure of withinpopulation variance, while the population variance component was taken as a measure of between-population variation.

We used a character state approach [46], treating life history traits and resistance in the different thermal environments as separate traits to calculate genetic correlations of traits across environments. Since individuals could only be assayed in one environment, we did not estimate covariance on the individual/unit level (by using the idh(trait):units covariance structure implemented in MCMCglmm). Variance and covariance for calculating genetic correlations $(\mathrm{rG})$ were estimated on the level of the pedigree by using the us (trait):animal variance components. Genetic correlations across environments were calculated as the covariance between traits divided by the square root of the product of both trait variances. Significance of genetic correlations across environments was assessed by estimating the proportion of estimates from the posterior distributions that overlapped with zero.

The effect of selection gradients imposed on life history traits by bacterial infection was analysed using only data from infected fish in separate thermal environments. GLMMs were fitted with weight or length as response variables, survival status as a fixed effect, density as a covariate, and population and animal as random effects.

\section{Results}

\section{Effects of thermal stress on life history traits and}

\section{pathogen resistance}

Thermal stress was visible in life history traits of sticklebacks after the acclimation and experimental period (Figure 1). Fish were on average smaller and lighter at $21^{\circ} \mathrm{C}$ than at $17^{\circ} \mathrm{C}$, but temperature only had significant effects on weight (Table 1). Models fitting separate intercepts but common slopes for populations showed a superior fit, indicating that the effect of temperature on weight was not significantly different between populations, whereas length and weight reached different levels in the populations (random intercepts, Table 1). Although there was considerable variation within families between thermal environments, random slope models did not produce superior model fits, indicating that $\mathrm{GxE}$ interactions were comparatively weak. Infection showed no significant effects on life history traits, probably owing to the short time period of the infection experiment (Table 1).

Infection strongly reduced survival (Figure 2). There was a significant difference between the survival of fish injected with PBS medium and fish injected with the Vibrio sp. isolate (Table 1). Control fish showed low levels of mortality towards the end of the experiment. Furthermore, temperature had strong effects on survival (Table 1). Infected fish held at the elevated water temperature $\left(21^{\circ} \mathrm{C}\right)$ died faster $(30.7 \%$ mortality within the first 12 hours of the experiment) and in higher numbers $(54.6 \%$ total mortality after 10 days post injection) than infected fish at $17^{\circ} \mathrm{C}(8.8 \%$ mortality in the first 12 hours, $35.2 \%$ total mortality after 10 days post injection). Superior fit of models containing random intercepts between populations and random slopes between families indicated that also survival rates differed among populations, and that reaction norms of survival rates varied significantly among families, thus representing GxE interactions (Table 1).

Effects of thermal stress on quantitative genetic variation We calculated the drift-based neutral divergence between populations for all populations combined (global $\mathrm{F}_{\mathrm{ST}}=$ 0.00825 , range $=-0.00055-0.03901)$ as well as for each population pair (pairwise $\mathrm{F}_{\mathrm{ST}}$, Sylt vs. Texel $\mathrm{F}_{\mathrm{ST}}=0.00339$, $P=0.19$, Sylt vs. Oosterschelde $\mathrm{F}_{\mathrm{ST}}=0.00926, P=0.01$, 



Figure 1 Effect of thermal stress on life history traits of different stickleback populations. Lines represent means (with standard errors) of length (A) and weight (B) of three different populations connecting different temperature treatments. Data from all fish were used.

Oosterschelde vs. Texel $\left.\mathrm{F}_{\mathrm{ST}}=0.02187, P=0.003\right)$. We observed small, but significant neutral differentiation between the Wadden Sea populations (Sylt and Texel) and the Oosterschelde. Our $\mathrm{F}_{\mathrm{ST}}$ estimates were somewhat smaller than previously reported $\mathrm{F}_{\mathrm{ST}}$ values for marine stickleback populations (range of 0.08 to 0.19 [47-49]), but reflected results obtained for other marine fish from the Wadden Sea [50].

For all investigated traits, quantitative genetic differentiation $\left(\mathrm{Q}_{\mathrm{ST}}\right)$ exceeded the overall neutral expectation $\left(\mathrm{F}_{\mathrm{ST}}\right.$, Figure 3 ) at $17^{\circ} \mathrm{C}$, suggesting directional selection is driving populations to different phenotypic optima at ambient temperatures [51]. Q evated temperature $\left(21^{\circ} \mathrm{C}\right.$, red lines in Figure 3$)$ than at ambient temperature $\left(17^{\circ} \mathrm{C}\right.$, blue lines in Figure 3) for all traits, owing to a trend showing a release of withinpopulation genetic variance of the selected traits $\left(\mathrm{V}_{\text {Animal }}\right.$, Table 2). This result was most obvious for survival, where $\mathrm{Q}_{\mathrm{ST}}$ values at elevated temperatures did not exceed neutral expectations, and divergent selection was only visible at ambient temperature. Differences in genetic differentiation between environments were smaller for weight than for length and survival, probably reflecting a stronger environmental influence on this trait that was also visible in the smaller unit variance components, capturing residuals and environmental variation (Figure 2, Table 2).

We found similar slopes of reaction norms between families and no significant evidence for GxE interactions

Table 1 Summary of the effects of thermal stress on life history traits and pathogen resistance

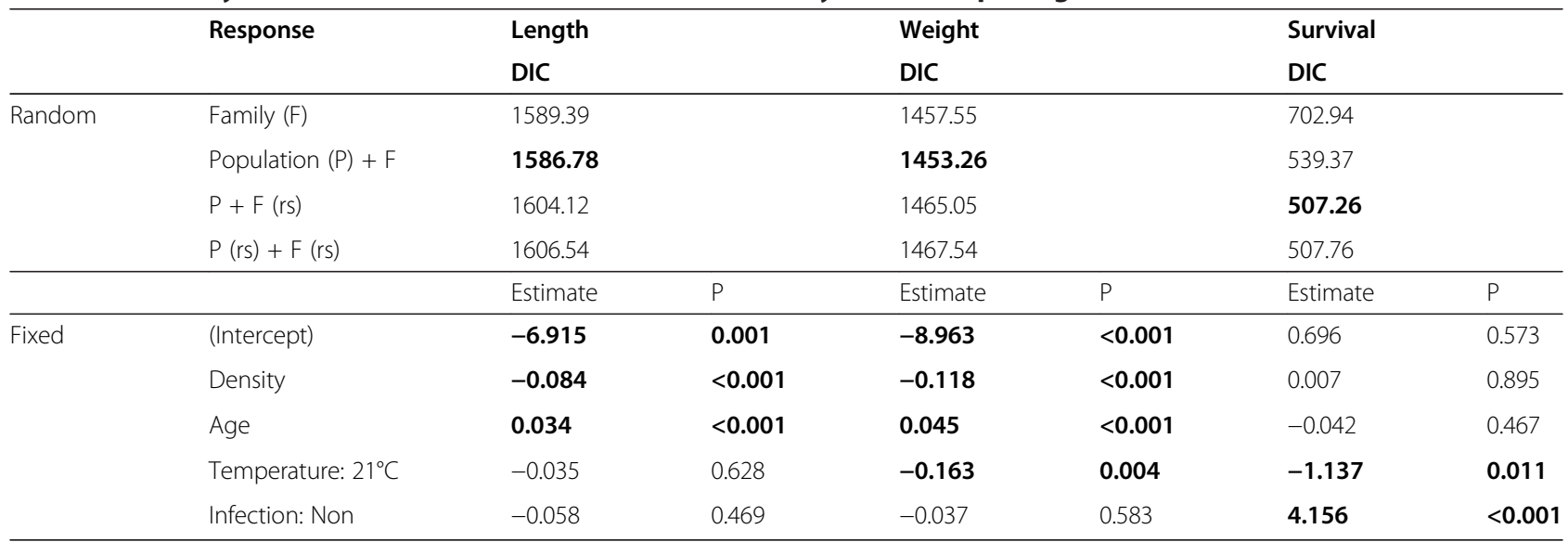

Generalized linear mixed models containing dependent variables length, weight (both Gaussian) and survival (binomial) with temperature and infection as fixed effects and density as a covariate. All models contained population and full-sibling family as random effects. Random slope models ( $r$ s) were fitted for both random factors and were retained when they provided better model fit judged by the Deviance Information Criterion (DIC). Fixed effect tables are based on the best fitting model. Best fitting models and significant effects are shown in bold. 


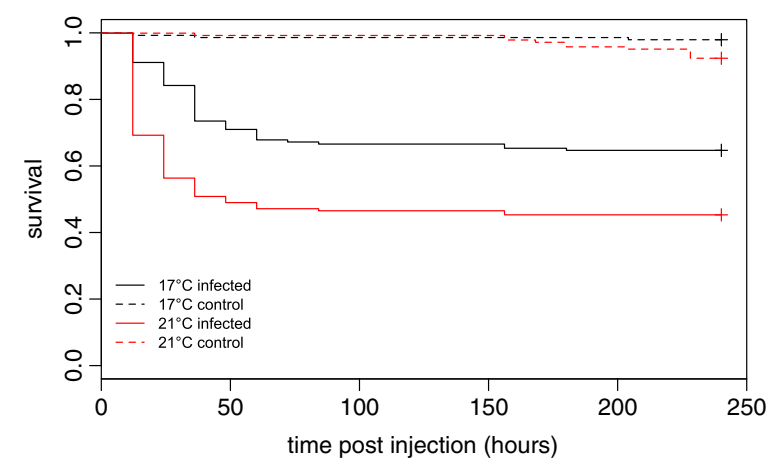

Figure 2 Survival plot of sticklebacks from different temperature treatments after infection with Vibrio sp. or PBS medium. Lines show means for all populations pooled.

for weight and length (Figure 4A, Table 1). This finding was supported by high and positive genetic correlation coefficients, that despite being lower than one indicate weak $\mathrm{GxE}$ interactions in response to thermal stress (Figure 4B, Table 2). Pathogen resistance, on the other hand, showed larger variation between environments with many crossing reaction norms (Figure 4A). Survival also showed strong $\mathrm{GxE}$ interactions and significant negative genetic correlations (Figure 4B, Table 2). Although resistance at ambient temperatures may be only a weak predictor for resistance under thermal stress, increased resistance at elevated temperature of some families in all populations (Figure 4A) may suggest that population mean fitness may be partly resilient to environmental change. Also, the increase in within-population genetic variation at elevated temperature (Table 2) shows that there is evolutionary potential to facilitate a response to changing climate conditions.

Pathogen-induced mortality also exerted correlated selection on life history traits. At ambient temperature, surviving fish were significantly longer (parameter estimate length: 0.649, $P<0.001$, Figure $5 \mathrm{~A}$ ) and heavier (parameter estimate weight: $0.745, P<0.001$, Figure $5 \mathrm{~B}$ ) than fish that died. At elevated temperature, differences between surviving and dead fish were smaller on average (parameter estimate length: $0.422, P=0.007$, parameter estimate weight: $0.382, P=0.008$ ), and selection differentials for body length increased in two out of three cases (Oosterschelde and Texel), whereas selection differentials for weight decreased uniformly in all populations.

\section{Discussion}

In this study, we tried to connect the effects of elevated temperature on life history traits, pathogen resistance,

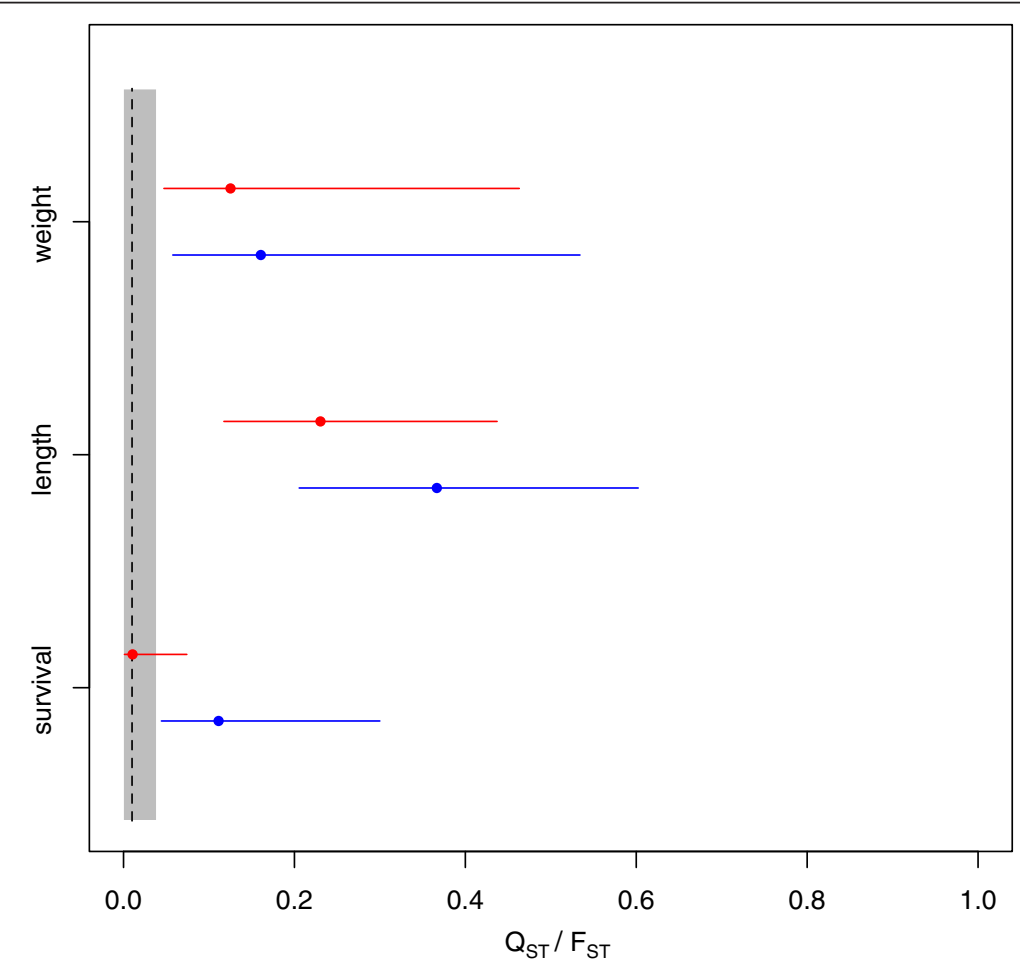

Figure 3 Quantitative trait and neutral marker differentiation of stickleback populations at different temperature treatments. The grey box represents the distribution range of global $F_{S T}$ estimates. Blue lines represent $95 \%$ confidence intervals of QST values for all phenotypic traits at $17^{\circ} \mathrm{C}$, while red lines represent $21^{\circ} \mathrm{C}$. Dots indicate position of highest densities of posterior distributions. All data were used for weight and length; only data from infected fish were used for survival. 
Table 2 Estimated variance components of different traits and temperature treatments

\begin{tabular}{|c|c|c|c|}
\hline & & $17^{\circ} \mathrm{C}$ & $21^{\circ} \mathrm{C}$ \\
\hline \multirow[t]{8}{*}{ Weight } & $17^{\circ} \mathrm{C}$ & $V_{A} 0.592(0.262-1.028)$ & Cov 0.862 (0.552 - 1.158) \\
\hline & & $V_{\text {pop }} 0.216(0.065-1.156)$ & $r_{G} 0.791(0.641-0.891)$ \\
\hline & & $V_{u} 0.375(0.128-0.578)$ & $\mathrm{P}_{\mathrm{rG}=0}<0.001$ \\
\hline & & $h^{2} 0.466(0.137-0.713)$ & \\
\hline & $21^{\circ} \mathrm{C}$ & & $V_{A} 0.785(0.478-1.036)$ \\
\hline & & & $V_{\text {pop }} 0.214(0.077-1.185)$ \\
\hline & & & $V_{u} 0.167(0.068-0.345)$ \\
\hline & & & $h^{2} 0.607(0.298-0.794)$ \\
\hline \multirow[t]{8}{*}{ Length } & $17^{\circ} \mathrm{C}$ & $V_{A} 0.210(0.094-0.568)$ & Cov $0.386(0.295-0.810)$ \\
\hline & & $V_{\text {pop }} 0.269(0.081-1.585)$ & $r_{G} 0.821(0.534-0.905)$ \\
\hline & & $V_{U} 0.698(0.467-0.866)$ & $P_{r G=0}<0.001$ \\
\hline & & $h^{2} 0.183(0.055-0.402)$ & \\
\hline & $21^{\circ} \mathrm{C}$ & & $V_{A} 0.478(0.264-0.946)$ \\
\hline & & & $V_{\text {pop }} 0.282(0.097-1.699)$ \\
\hline & & & $V_{u} 0.453(0.181-0.602)$ \\
\hline & & & $h^{2} 0.345(0.143-0.647)$ \\
\hline \multirow[t]{8}{*}{ Survival } & $17^{\circ} \mathrm{C}$ & $V_{A} 0.834(0.239-7.563)$ & Cov $-2.655(-377.98--0.387)$ \\
\hline & & $V_{\text {pop }} 0.351(0.055-5.407)$ & $r_{G}-0.884(-0.992--0.073)$ \\
\hline & & $V_{\cup} 1^{*}$ & $P_{r G=0}<0.001$ \\
\hline & & $h^{2} n e^{*}$ & \\
\hline & $21^{\circ} \mathrm{C}$ & & $V_{A} 6.604(0.616-100.668)$ \\
\hline & & & $V_{\text {pop }} 0.701(0.203-4.261)$ \\
\hline & & & $V_{U} 1^{*}$ \\
\hline & & & $h^{2} n e^{*}$ \\
\hline
\end{tabular}

Variance components for $\mathrm{V}_{\text {Animal, }}, \mathrm{V}_{\text {Population, }} \mathrm{V}_{\text {Unit }}$ (representing residual variation including environmental effects) and resulting heritability ( $\mathrm{h}^{2}$ ) as well as genetic correlations across environments $\left(r_{\mathrm{G}}\right)$ with $95 \%$ confidence intervals. Estimates are based on standardized values. ${ }^{*}$ fixed residual variation because categorical traits were used and heritabilities were not estimable.

and population-specific potential for evolutionary responses in marine sticklebacks. After only a short acclimation period at elevated temperature, we found impacts of thermal stress on fish weight and especially survival after infection. Furthermore, thermal stress tended to release cryptic within-population genetic variation $\left(V_{A}\right)$, which led to reduced genetic differentiation $\left(\mathrm{Q}_{\mathrm{ST}}\right)$ between populations. While life history traits showed positive genetic correlations between temperatures and only weak, nonsignificant GxE interactions, thermal stress led to negative genetic correlations across environments and strong GxE interactions in pathogen resistance. These trait-specific patterns indicate that evolutionary potential of life history traits (with positive genetic correlations across environments) can be reliably predicted from levels of standing genetic variation. For survival from infection, on the other hand, negative genetic correlations across environments indicate that current genetic variation in resistance may be a weak predictor for future resistance evolution, highlighting the crucial importance of disease in adaptation to new environmental conditions potentially favouring pathogens and parasites.

In general, thermal stress is likely to affect fish biochemistry, physiology and behaviour [52], and can negatively influence fish development and survival [53]. Interactions between elevated temperatures and decreased size and weight have been demonstrated in several studies [32,54,55], and it is believed that higher temperatures lead to lower food conversion efficiency in temperate sticklebacks, as energy is preferably used to maintain high metabolic rate [55]. Fish from Sylt were less affected by thermal stress throughout the experiment. This indicates the presence of different phenotypic optima as well as different thermal tolerances among the studied populations. Temperature preferences of sticklebacks for ideal growth were previously reported in the range between $15-18^{\circ} \mathrm{C}[32,33]$, at $19^{\circ} \mathrm{C}$ [56], and also at $21,7^{\circ} \mathrm{C}$ [57], showing that thermal 


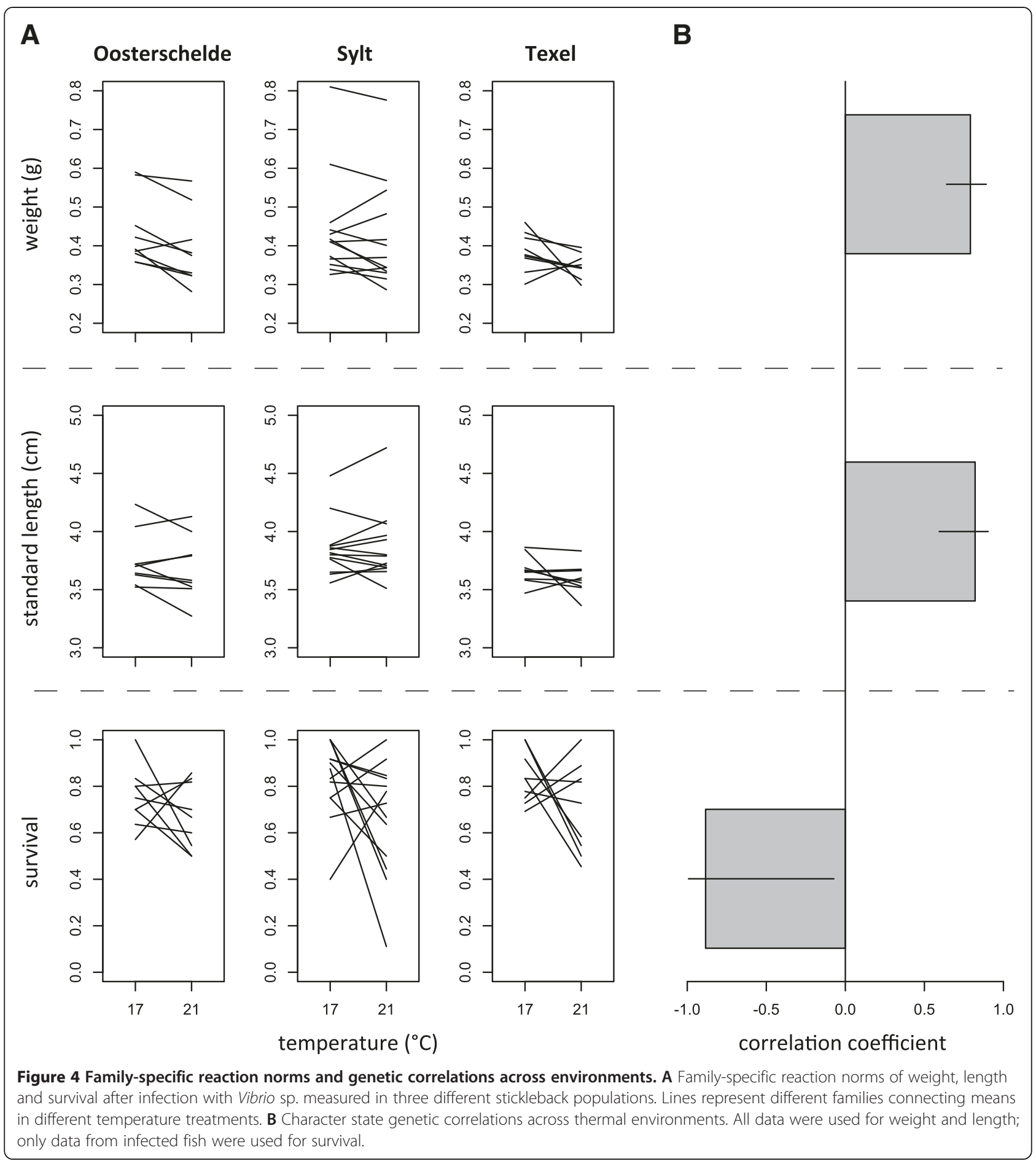

optima can differ substantially between populations. Temperate species are able to adapt and shift their thermal window through changes in mitochondrial densities as well as via other molecular and systemic adjustments [58]. The wide range of thermal optima reported in the literature in conjunction with our results on quantitative genetic differentiation (Figure 3) seem, however, to suggest that stickleback populations harbour substantial amounts of standing genetic variation and can adapt quickly to local environmental conditions.

The reduced sensitivity of the Sylt population can either be explained by increased tolerance due to phenotypic plasticity, or alternatively, by more favourable experimental conditions matching local conditions when compared 

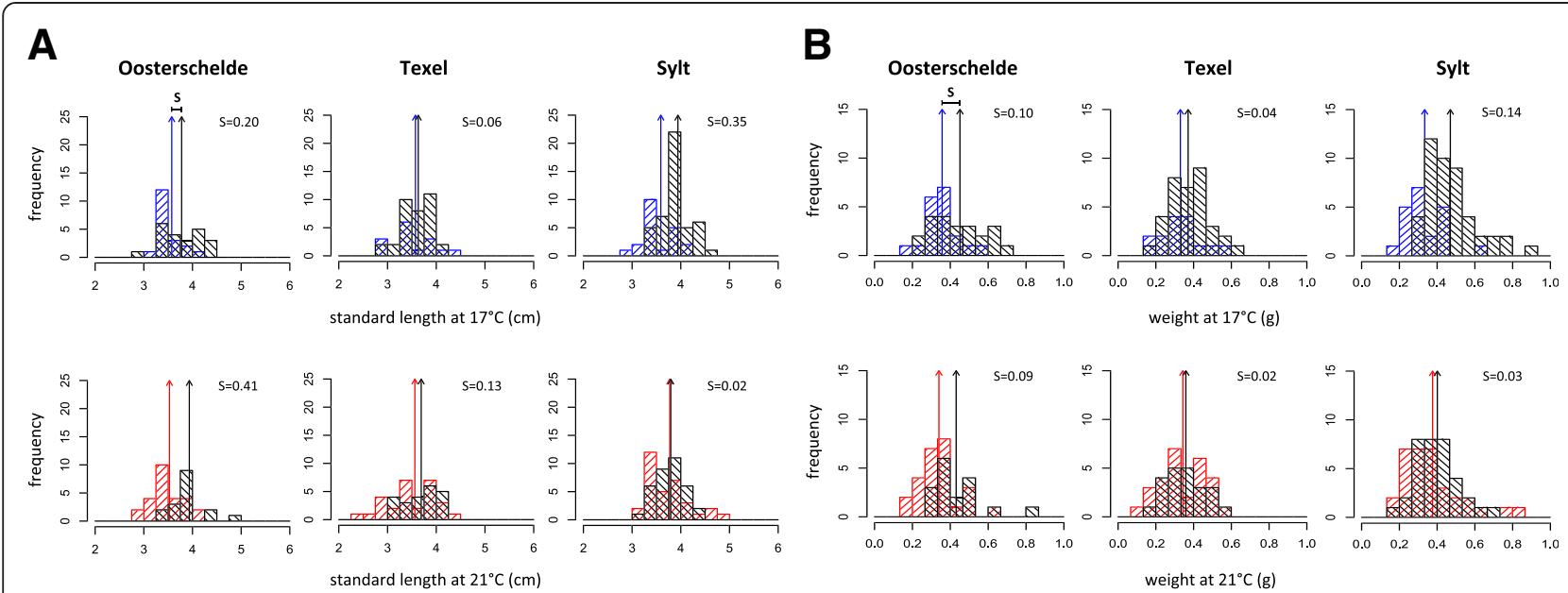

Figure 5 Selection gradients of life history traits under pathogen induced selection. Length (A) and weight (B) of dead fish (red bars = died at $17^{\circ} \mathrm{C}$, blue bars $=$ died at $21^{\circ} \mathrm{C}$ ) and surviving fish (black bars) from different populations. Arrows show the means of the respective distributions marking the selection differential S (mean trait survived - mean trait dead) resulting from pathogen-induced mortality. Only data from infected fish were used for selective gradients.

to the other populations. We can assume that the allopatric populations from Oosterschelde and Texel were not only exposed to temperature stress but also had to cope with different water chemistry (our common garden experiment used seawater from Sylt). This might have led to less favourable overall conditions amplifying negative effects of temperature stress, thus resulting in a stronger decline of weight at elevated temperature. Although we showed that short-term acclimation to increased temperature negatively influenced fish development, previous studies have shown that long-term acclimation to higher temperatures (within the natural range) can potentially lead to enhanced development and increased growth rates [58-60]. The Sylt stickleback populations, on the other hand, continue to show decreased body size when exposed to higher temperatures throughout their lifetime [35], indicating that our thermal conditions exceeded their potential for acclimation, especially during early phases of development. Our results presented here thus support our previous results on a different trait. While we previously found differences in size during the whole ontogeny $[35,61]$, in the present study we did not observe significant influences of thermal stress on size in later life stages. Rather, we observed a response in weight. Although we could not track individual fish weight over time (i.e. we did not measure weight before the experimental treatment), we think it is highly unlikely that we accidentally produced our results by pre-existing bias. Since fish were randomly assigned to treatments, the chances of assigning heavier fish to the cold treatment in 23 out of 31 families used is very small $(P=0.003)$. Therefore, weight differences more likely represent effects of our treatment than pure chance. Additionally, we have previously shown that the efficiency of mitochondrial energy metabolism is reduced at $21^{\circ} \mathrm{C}$ [61], leading to higher energy demands and consequently lower resource availability. Increased use of reserves to cope with increased energy demand will lead to a drop in weight, and reduced growth can then be considered a secondary consequence of less available resources.

Our experiment also revealed that elevated temperatures have profound impacts on pathogen resistance of marine stickleback populations. Infected fish held in water at $21^{\circ} \mathrm{C}$ died faster and showed higher overall mortality than infected fish at $17^{\circ} \mathrm{C}$. Suboptimal temperatures may influence innate immunity directly [62] or indirectly as a result of stress-linked overproduction of immunosuppressive cortisol [63]. It has also been shown that elevated temperature negatively affects the resistance of fish to diseases by affecting antibody production and leucocyte activity [12,64]. Either way, stressed organisms are likely to be more susceptible to infectious diseases than non-stressed ones [65]. Increased susceptibility due to stress can additionally be amplified by increased virulence of pathogens at higher temperatures. Vibrios are generally favoured at warmer temperatures [20,21], and the temperature optimum for Vibrio tubiashii is reported to be at $25^{\circ} \mathrm{C}$ [66]. We can thus assume that the elevated temperature of $21^{\circ} \mathrm{C}$ supported faster development and a higher concentration of bacteria in the fish resulting in higher pathogenicity. Additionally, surviving fish were significantly longer and heavier, with weight reacting faster to environmental change than length. Especially for weight, we consistently observed decreased selection differentials at elevated temperatures. The altered response to selection imposed by infection might indicate that responses of other fitness components also can change unpredictably in changing environments. 
Such changes in responses to selection on single traits will ultimately also feed back on past and future evolutionary responses of the host. By using a $\mathrm{Q}_{\mathrm{ST}}-\mathrm{F}_{\mathrm{ST}}$ approach, we revealed that, especially for length and survival, the release of within-population genetic variance by environmental stress led to lower $\mathrm{Q}_{\mathrm{ST}}$ values (even though betweenpopulation variances were not reduced). While the genetic components underlying phenotypic variation were less divergent for traits assayed at higher temperature $\left(21^{\circ}\right)$, thermal stress increased genetic variance $\left(\mathrm{V}_{\mathrm{Animal}}\right)$ and heritability) for most of the selected traits (Table 2). The effects of environmental change on quantitative genetic differentiation have only rarely been addressed. Hoffmann and Merilä [67] summarized several outcomes of how unfavourable conditions can affect the genetic variation of a trait. First, stressful conditions can increase genetic variation in traits by increasing rates of recombination and mutation [68], by removing low fitness alleles due to selection [69], or because phenotypic differences among genotypes are only expressed as resources become limiting [70]. Second, genetic variance and heritability are decreased by increased environmental variation [71] or due to limited genetic potential of organisms under poor nutrition [72]. And third, stressful conditions have unpredictable effects on the genetic variation of a trait $[18,73,74]$. Our comparison of indices of population differentiation in quantitative traits ( $_{\text {ST }}$ of length, weight and survival) and neutral genetic divergence $\left(\mathrm{F}_{\mathrm{ST}}\right.$ of microsatellite markers) showed that divergent directional selection was the driving force for reaching different optima in length, weight and survival at $17^{\circ} \mathrm{C}$ in our stickleback populations $\left(\mathrm{Q}_{\mathrm{ST}}>\mathrm{F}_{\mathrm{ST}}\right)$.

Even if the comparison between $\mathrm{Q}_{\mathrm{ST}}$ - and $\mathrm{F}_{\mathrm{ST}}$ - values can reveal the presence and type of selection acting on traits [75-78], an essential requirement for evolutionary change is the amount of genetic variability expressed for the trait under selection [79]. We observed positive genetic correlations between character states of life history traits assayed at different temperatures. Although slopes of the genetic correlations across environments were significantly different than 1 , family-specific reaction norms were rather flat, indicating that no significant genotype by environment interactions (GxE) affected life history traits. In contrast, pathogen resistance showed a negative genetic correlation across environments. This reversal of genetic effects is probably due to changing environment-dependent virulence mechanisms of the pathogen interacting differently with host genotypes, i.e. $\mathrm{G}_{\text {Pathogen }} \mathrm{x} \mathrm{G}_{\text {Host }} \mathrm{xE}$ or $\left(\mathrm{G}_{\text {Pathogen }} \mathrm{xE}\right)$ $x\left(G_{\text {Host }} x E\right)$ interactions, rather than to pure host genetic effects, i.e. $\mathrm{G}_{\text {Host }} \mathrm{xE}$ interactions. On the other hand, some families within each of the populations showed improved performance at elevated temperature, which may lead to higher fitness in changing environments and adaptation of the population as a whole.
The maximal rate of adaptation is of crucial importance for estimating the ecological and evolutionary consequences of climatic warming. Populations need to shift the distribution of phenotypes to maintain optimal fitness in the changed environment [14]. Fast adaptation to rising temperature either requires short generation times or a substantial amount of standing genetic variation within populations [80]. Even though we found evolutionary potential in both environments, the negative genetic correlation in pathogen resistance between thermal environments demonstrates that adaptation to current conditions can, in certain cases, be a weak predictor for performance in changing environments. The negative genetic correlation across environments in survival might also have changed the selection gradients of associated life history traits, which might indicate that due to pathogen-induced selection, responses of other fitness components can be variable under unfavourable conditions.

\section{Conclusion}

Our study shows that thermal stress can negatively impact life history traits and pathogen resistance of marine three-spined sticklebacks. Moreover, environmental stress led to negative genetic correlations across environments for pathogen resistance. Although we found evolutionary potential in both thermal environments, it is hard to predict the capacity for adaptation by selection of pathogen resistant genotypes from ambient conditions. While positive genetic correlations of life history traits between environments indicate similar responses to selection, the altered selective gradient imposed by infection shows that responses of vital fitness components can change unpredictably in changing environments.

\section{Availability of supporting Data}

The data sets supporting the results of this article are available in the Pangaea repository http://doi.org/10.1594/ PANGAEA.833937 [81].

\section{Competing interests}

The authors declare that they have no competing interests.

\section{Authors' contributions}

FSM wrote the manuscript, conducted the fish breeding as well as the experiment, dissected the fish, and was involved in designing the project, genotyping and performing statistical analyses. LNSS was involved in designing the project, running pilot studies and writing the manuscript KMW was involved in designing the project, genotyping, performing statistical analyses and writing the manuscript. All authors read and approved the final manuscript.

\section{Acknowledgements}

We would like to thank Nina Eschweiler, Moritz Pockberger, Carolin Wendling, René Gerrits, Bert Sinke and David Thieltges for help with fishing in Germany and the Netherlands. René Gerrits and Tobias Mayr for taking care of the fish. Three anonymous reviewers gave helpful comments on previous versions of the manuscript. The study was funded by DFG Emmy Noether Programme grant WE 4614/1-1. 
Received: 13 November 2013 Accepted: 14 July 2014

Published: 26 July 2014

\section{References}

1. Hudson PJ, Rizzol IA, Grenfell BT, Heesterbeek H, Dobson AP: The ecology of wildlife diseases. Oxford: Oxford University Press; 2002.

2. Altizer $S$, Harvell D, Friedle E: Rapid evolutionary dynamics and disease threats to biodiversity. Trends Ecol Evol 2003, 18(11):589-596.

3. Cattadori IM, Haydon DT, Hudson PJ: Parasites and climate synchronize red grouse populations. Nature 2005, 433(7027):737-741.

4. Harvell CD, Mitchell CE, Ward JR, Altizer S, Dobson AP, Ostfeld RS, Samuel MD: Ecology - Climate warming and disease risks for terrestrial and marine biota. Science 2002, 296(5576):2158-2162.

5. Shiah FK, Ducklow HW: Temperature and substrate regulation of bacterial abundance, production and specific growth-rate in chesapeake bay, USA. Mar Ecol Prog Ser 1994, 103(3):297-308.

6. Karvonen A, Rintamaki P, Jokela J, Valtonen ET: Increasing water temperature and disease risks in aquatic systems: Climate change increases the risk of some, but not all, diseases. Int J Parasitol 2010, 40(13):1483-1488.

7. Pounds JA, Bustamante MR, Coloma LA, Consuegra JA, Fogden MPL, Foster PN, La Marca E, Masters KL, Merino-Viteri A, Puschendorf R, Ron SR, Sánchez-Azofeifa GA, Still CJ, Young BE: Widespread amphibian extinctions from epidemic disease driven by global warming. Nature 2006, 439(7073):161-167.

8. Kim K, Harvell CD, Kim PD, Smith GW, Merkel SM: Fungal disease resistance of Caribbean sea fan corals (Gorgonia spp.). Mar Biol 2000, 136(2):259-267.

9. Lafferty KD: The ecology of climate change and infectious diseases. Ecology 2009, 90(4):888-900.

10. Harvell CD, Kim K, Burkholder JM, Colwell RR, Epstein PR, Grimes DJ, Hofmann EE, Lipp EK, Osterhaus AD, nbsp, Overstreet RM, Porter JW, Smith GW, Vasta GR: Emerging Marine Diseases-Climate Links and Anthropogenic Factors. Science 1999, 285(5433):1505-1510.

11. Arnell NW: Climate change and global water resources. Glob Environ Change-Human Policy Dimens 1999, 9:S31-S49.

12. Alborali L: Climatic variations related to fish diseases and production. Vet Res Commun 2006, 30:93-97.

13. Harley CDG, Hughes AR, Hultgren KM, Miner BG, Sorte CJB, Thornber CS, Rodriguez LF, Tomanek L, Williams SL: The impacts of climate change in coastal marine systems. Ecol Lett 2006, 9(2):228-241.

14. Visser ME: Keeping up with a warming world; assessing the rate of adaptation to climate change. Proc R Soc B-Biol Sci 2008, 275(1635):649-659.

15. Eliason EJ, Clark TD, Hague MJ, Hanson LM, Gallagher ZS, Jeffries KM, Gale MK, Patterson DA, Hinch SG, Farrell AP: Differences in Thermal Tolerance Among Sockeye Salmon Populations. Science 2011, 332(6025):109-112.

16. Perry AL, Low PJ, Ellis JR, Reynolds JD: Climate change and distribution shifts in marine fishes. Science 2005, 308(5730):1912-1915.

17. Gienapp P, Teplitsky C, Alho JS, Mills JA, Merila J: Climate change and evolution: disentangling environmental and genetic responses. Mol Ecol 2008, 17(1):167-178

18. McGuigan K, Nishimura N, Currey M, Hurwit D, Cresko WA: Cryptic genetic variation and body size evolution in threespine stickleback. Evolution 2011, 65(4):1203-1211.

19. Austin B, Austin DA: Bacterial Fish Pathogens: Diseases of Farmed and Wild Fish. Chichester: Springer; 2007.

20. Thompson JR, Randa MA, Marcelino LA, Tomita-Mitchell A, Lim E, Polz MF: Diversity and dynamics of a north Atlantic coastal Vibrio community. Appl Environ Microbiol 2004, 70(7):4103-4110.

21. Vezzulli L, Previati M, Pruzzo C, Marchese A, Bourne DG, Cerrano C, VibrioSea C: Vibrio infections triggering mass mortality events in a warming Mediterranean Sea. Environ Microbiol 2010, 12(7):2007-2019.

22. Oberbeckmann S, Fuchs BM, Meiners M, Wichels A, Wiltshire KH, Gerdts G: Seasonal Dynamics and Modeling of a Vibrio Community in Coastal Waters of the North Sea. Microb Ecol 2012, 63(3):543-551.

23. Elston RA, Hasegawa H, Humphrey KL, Polyak IK, Hase CC: Re-emergence of Vibrio tubiashii in bivalve shellfish aquaculture: severity, environmental drivers, geographic extent and management. Dis Aquat Org 2008, 82(2):119-134

24. Hada HS, West PA, Lee JV, Stemmler J, Colwell RR: Vibrio tubiashii sp-nov, a pathogen of bivalve mollusks. Int J Syst Bacteriol 1984, 34(1):1-4.
25. Egidius E: Vibriosis-pathogenicity and pathology - a review. Aquaculture 1987, 67(1-2):15-28.

26. Austin B, Austin D, Sutherland R, Thompson F, Swings J: Pathogenicity of vibrios to rainbow trout (Oncorhynchus mykiss, Walbaum) and Artemia nauplii. Environ Microbiol 2005, 7(9):1488-1495.

27. Woo PTK, Bruno DW: Fish Diseases and Disorders, Volume 3: Viral, Bacterial and Fungal Infections, 2nd Edition Preface to the. 1st edition; 2011.

28. Barber I, Arnott SA, Braithwaite VA, Andrew J, Huntingford FA: Indirect fitness consequences of mate choice in sticklebacks: offspring of brighter males grow slowly but resist parasitic infections. Proc $R \mathrm{SOC}$ B-Biol Sci 2001, 268(1462):71-76.

29. Kurtz J, Kalbe M, Aeschlimann PB, Haberli MA, Wegner KM, Reusch TBH, Milinski M: Major histocompatibility complex diversity influences parasite resistance and innate immunity in sticklebacks. Proc R Soc B-Biol Sci 2004, 271(1535):197-204

30. Wegner KM, Kalbe M, Milinski M, Reusch TBH: Mortality selection during the 2003 European heat wave in three-spined sticklebacks: effects of parasites and MHC genotype. BMC Evol Biol 2008, 8:124

31. Jordan $C M$, Garside ET: Upper lethal temperatures of threespine stickleback, Gasterosteus aculeatus (L), in relation to thermal and osmotic acclimation, ambient salinity and size. Can J Zool 1972, 50(11):1405

32. Macnab V, Barber I: Some (worms) like it hot: fish parasites grow faster in warmer water, and alter host thermal preferences. Glob Chang Biol 2012, 18(5):1540-1548.

33. Garside ET, Heinze DG, Barbour SE: Thermal preference in relation to salinity in threespine stickleback, Gasterosteus aculetus $L$, with an interpredation of its significance. Can J Zool-Revue Canadienne De Zoologie 1977, 55(3):590-594.

34. Sheppard C: Sea surface temperature 1871-2099 in 14 cells around the United Kingdom. Mar Pollut Bull 2004, 49(1-2):12-16.

35. Ramler D, Mitteroecker $P$, Shama $L$, Wegner $K$, Ahnelt $H$ : Nonlinear effects of temperature on body form and developmental canalization in the threespine stickleback. J Evol Biol 2014, 27:497-507.

36. Schär C, Vidale PL, Lüthi D, Frei C, Häberli C, Liniger MA, Appenzeller C The role of increasing temperature variability in European summer heatwaves. Nature 2004, 427(6972):332-336.

37. Largiader CR, Fries V, Kobler B, Bakker TCM: Isolation and characterization of microsatellite loci from the three-spined stickleback (Gasterosteus aculeatus L.). Mol Ecol 1999, 8(2):342-344.

38. Peichel CL, Nereng KS, Ohgi KA, Cole BLE, Colosimo PF, Buerkle CA, Schluter $D$, Kingsley DM: The genetic architecture of divergence between threespine stickleback species. Nature 2001, 414(6866):901-905.

39. Weir BS, Cockerham CC: Estimating F-statistics for the analysis of population-structure. Evolution 1984, 38(6):1358-1370.

40. Belkhir KBP, Chikhi L, Raufaste N, Bonhomme F: GENETIX 4.05, logiciel sous Windows TM pour la génétique des populations. In Montpellier. France: Laboratoire Génome, Populations, Interactions, Université de Montpellier II; 1996:2004.

41. Whitlock MC, Guillaume F: Testing for spatially divergent selection: comparing OST to FST. Genetics 2009, 183(3):1055-1063.

42. Hadfield JD: MCMC Methods for Multi-Response Generalized Linear Mixed Models: The MCMCgImm R Package. J Stat Softw 2010, 33(2):1-22.

43. R Development Core Team: $R$ : A language and environment for statistical computing R Foundation for Statistical Computing; 2008

44. Spiegelhalter DJ, Best NG, Carlin BR, van der Linde A: Bayesian measures of model complexity and fit. J R Stat Soc Series B-Stat Methodol 2002, 64:583-616.

45. Spitze K: Population-structure in Daphnia-Obtusa - quantitative genetic and allozymic variation. Genetics 1993, 135(2):367-374.

46. Falconer DS: The Problem of Environment and Selection. Am Nat 1952, 86(830):293-298

47. Leinonen T, Cano JM, Makinen H, Merila J: Contrasting patterns of body shape and neutral genetic divergence in marine and lake populations of threespine sticklebacks. J Evol Biol 2006, 19(6):1803-1812.

48. Raeymaekers JAM, Van Houdt JKJ, Larmuseau MHD, Geldof S, Volckaert FAM: Divergent selection as revealed by P-ST and QTL-based F-ST in three-spined stickleback (Gasterosteus aculeatus) populations along a coastal-inland gradient. Mol Ecol 2007, 16(4):891-905.

49. Reusch TBH, Wegner KM, Kalbe M: Rapid genetic divergence in postglacial populations of threespine stickleback (Gasterosteus aculeatus): the role 
of habitat type, drainage and geographical proximity. Mol Ecol 2001, 10(10):2435-2445.

50. Hoarau G, Rijnsdorp AD, Van der Veer HW, Stam WT, Olsen JL: Population structure of plaice (Pleuronectes platessa L.) in northern Europe: microsatellites revealed large-scale spatial and temporal homogeneity. Mol Ecol 2002, 11(7):1165-1176

51. Merila J, Crnokrak P: Comparison of genetic differentiation at marker loci and quantitative traits. J Evol Biol 2001, 14(6):892-903.

52. Beitinger TL, Bennett WA, McCauley RW: Temperature tolerances of North American freshwater fishes exposed to dynamic changes in temperature. Environ Biol Fish 2000, 58(3):237-275.

53. Dominguez M, Takemura A, Tsuchiya M, Nakamura S: Impact of different environmental factors on the circulating immunoglobulin levels in the Nile tilapia, Oreochromis niloticus. Aquaculture 2004, 241(1-4):491-500.

54. Donelson JM, Munday PL, McCormick MI, Pitcher CR: Rapid transgenerational acclimation of a tropical reef fish to climate change. Nat Clim Chang 2012, 2(1):30-32.

55. Guderley $\mathrm{H}$, Leroy PH: Family origin and the response of threespine stickleback, Gasterosteus aculeatus, to thermal acclimation. J Comp Physiol B-Biochem Syst Environ Physiol 2001, 171(2):91-101.

56. Allen JRM, Wootton RJ: The effect of ration and temperature on the growth of the 3-spined stickleback, Gasterosteus aculeatus L. J Fish Biol 1982, 20(4):409-422.

57. Lefebure R, Larsson S, Bystrom P: A temperature-dependent growth model for the three-spined stickleback Gasterosteus aculeatus. J Fish Biol 2011, 79(7):1815-1827.

58. Portner HO: Climate change and temperature-dependent biogeography: oxygen limitation of thermal tolerance in animals. Naturwissenschaften 2001, 88(4):137-146.

59. Green BS, Fisher R: Temperature influences swimming speed, growth and larval duration in coral reef fish larvae. J Exp Mar Biol Ecol 2004, 299(1):115-132.

60. Sponaugle S, Grorud-Colvert K, Pinkard D: Temperature-mediated variation in early life history traits and recruitment success of the coral reef fish Thalassoma bifasciatum in the Florida Keys. Mar Ecol Prog Ser 2006, 308:1-15.

61. Shama L, Strobel A, Mark F, Wegner K: Transgenerational plasticity in marine sticklebacks: maternal effects mediate impacts of a warming ocean. Funct Ecol 2014, doi:10.1111/1365-2435.12280

62. Nikoskelainen S, Bylund G, Lilius EM: Effect of environmental temperature on rainbow trout (Oncorhynchus mykiss) innate immunity. Dev Comp Immunol 2004, 28(6):581-592.

63. Weyts FAA, Cohen N, Flik G, Verburg-van Kemenade BML: Interactions between the immune system and the hypothalamo-pituitary-interrenal axis in fish. Fish Shellfish Immunol 1999, 9(1):1-20.

64. Landis SH, Kalbe M, Reusch TBH, Roth O: Consistent Pattern of Local Adaptation during an Experimental Heat Wave in a Pipefish-Trematode Host-Parasite System. PLoS One 2012, 7:1.

65. Lafferty KD, Holt RD: How should environmental stress affect the population dynamics of disease? Ecol Lett 2003, 6(7):654-664.

66. Temperton B, Thomas S, Tait K, Parry H, Emery M, Allen M, Quinn J, MacGrath J, Gilbert J: Permanent draft genome sequence of Vibrio tubiashii strain NCIMB 1337 (ATCC19106). Stand Genomic Sci 2011, 4(2):183-190.

67. Hoffmann AA, Merila J: Heritable variation and evolution under favourable and unfavourable conditions. Trends Ecol Evol 1999, 14(3):96-101.

68. Hoffmann AA, Parsons PA: Evolutionary genetics and environmental stress. 1991

69. Kawecki TJ, Barton NH, Fry JD: Mutational collapse of fitness in marginal habitats and the evolution of ecological specialisation. J Evol Biol 1997, 10(3):407-429

70. Hartl DL, Dykhuizen DE, Dean AM: Limits of adaptation - the evolution of selective neutrality. Genetics 1985, 111(3):655-674

71. Blum A: Plant Breeding for Stress Environments: CRC Press. 1988.

72. Gebhardthenrich SG, Vannoordwijk AJ: Nestling growth in the great tit 1 . Heritability estimates under different environmental conditions. J Evol Biol 1991, 4(3):341-362.

73. Ebert D, Yampolsky L, Stearns SC: Genetics of life-history in daphnia-magna. 1. Heritabilities at two food levels. Heredity 1993, 70:335-343.

74. Gavrilets S, Scheiner SM: The genetics of phenotypic plasticity 6 . theoretical predicitions for directional selection. J Evol Biol 1993, 6(1):49-68.
75. Knopp T, Cano JM, Crochet P-A, Merila J: Contrasting levels of variation in neutral and quantitative genetic loci on island populations of moor frogs (Rana arvalis). Conserv Genet 2007, 8(1):45-56.

76. Leinonen T, O'Hara RB, Cano JM, Merila J: Comparative studies of quantitative trait and neutral marker divergence: a meta-analysis. J Evol Biol 2008, 21(1):1-17.

77. Roberge C, Guderley H, Bernatchez L: Genomewide identification of genes under directional selection: Gene transcription Q(ST) scan in diverging Atlantic salmon subpopulations. Genetics 2007, 177(2):1011-1022.

78. Tubiash HS, Chanley PE, Leif-Son E: Bacillary necrosis, a disease of larval and juvenile bivalve mol-lusks. I. Etiology and epizootiology. J Bacteriol 1965, 90(4):1036-1044.

79. Charmantier A, Garant D: Environmental quality and evolutionary potential: lessons from wild populations. Proc R Soc B-Biol Sci 2005, 272(1571):1415-1425.

80. Poertner HO, Farrell AP: Ecology Physiology and climate change. Science 2008, 322(5902):690-692

81. Schade FM, Shama LNS, Wegner KM: Data from: Impact of thermal stress on evolutionary trajectories of pathogen resistance in three-spined stickleback (Gasterosteus aculeatus). Pangaea 2014, http://doi.org/10.1594/ PANGAEA.833937.

doi:10.1186/s12862-014-0164-5

Cite this article as: Schade et al:: Impact of thermal stress on

evolutionary trajectories of pathogen resistance in three-spined stickleback (Gasterosteus aculeatus). BMC Evolutionary Biology 2014 14:164.

\section{Submit your next manuscript to BioMed Central and take full advantage of:}

- Convenient online submission

- Thorough peer review

- No space constraints or color figure charges

- Immediate publication on acceptance

- Inclusion in PubMed, CAS, Scopus and Google Scholar

- Research which is freely available for redistribution 